\title{
The Herding Behavior on the Karachi Stock Exchange Pakistan
}

\author{
Fasiha Kiran* and Naimat U. Khan**
}

\begin{abstract}
This paper analyzes herding behavior on the Karachi Stock Exchange (KSE) for a sample of 200 firms over a period of 10 years from 2004 to 2014 using two different methodologies presented by Christie and Huang (1995) and Chang et al. (2000). Herding can be defined as when investors neglect their own information and take after different investors' investment choices. One of the contributions of this paper is to explore herding behavior not only on aggregate data of 200 firms but also on the basis of individual company as well. This study shows mixed results of herding based for the two methods employed in the research. Using the index data, the results on the basis of Christie and Huang (2004) method indicate presence of herding in the stock market while the results of Chang et al. (2000) method show an absence of herding behavior. However, individual company shows the existence of herding behavior; it refers that company follow each other during investment process. The absence of herding behavior shows that investors do not follow each other and use its own rationale for investment. The rationale behind this research was to investigate herding behavior in Karachi stock exchange because little work has been done regarding herding in Pakistan.
\end{abstract}

Key words: Herding, Anomaly, Efficient Market Hypothesis, Behavioral Finance, Pakistan

*Fasiha Kiran is a Post-Graduate Scholar at Institute of Management Studies, University of Peshawar Pakistan.

**Naimat U. Khan (PhD) is an Assistant Professor at Institute of Management Studies, University of Peshawar Pakistan. Naimat can be contacted via naimtims@yahoo.com 